Centro de Estudios Constitucionales de Chile Universidad de Talca

"La relevancia que las Cortes de Apelaciones del denominado Norte Grande han atribuido a los vínculos de familia de inmigrantes, para efectos de acoger las acciones de amparo que buscan revocar las órdenes de expulsión" Alexis Mondaca Miranda

\title{
LA RELEVANCIA QUE LAS CORTES DE APELACIONES DEL DENOMINADO NORTE GRANDE HAN ATRIBUIDO A LOS VÍNCULOS DE FAMILIA DE INMIGRANTES, PARA EFECTOS DE ACOGER LAS ACCIONES DE AMPARO QUE BUSCAN REVOCAR LAS ÓRDENES DE EXPULSIÓN
}

On the importance aTTACHED by the Courts of Appeal of the NorThern Area of ChILE TO BONDS of FAMILY OF IMMIGRANTS For PUPOSES OF UPHOLDING PETITITIONS FOR INJUCTIVE RELIEF THAT SEEK TO ABROGATE ORDERS OF EXPULSION

Alexis Mondaca Miranda ${ }^{*}$ Universidad Católica del Norte amondaca@ucn.cl

\section{INTRODUCCIÓN}

En las últimas décadas han ingresado a nuestro país importantes flujos migratorios, tal como lo demuestran las estadísticas. En conformidad a las cifras del INE, el siguiente ha sido el crecimiento de la población extranjera en Chile entre 1982 y 2014: 83.805 (Censo 1982); 105.070 (Censo 1992); 184.464 (Censo 2002) y 441.529 (estimación 2014). No se incluyen en estas cifras a quienes no han regularizado su situación de residencia; por lo tanto, el número total de extranjeros que habitan en Chile debe aumentarse considerablemente.

Después de la Región Metropolitana, que concentra el 61,5\% de la población total de inmigrantes, la zona que más extranjeros ha recibido ha sido el extremo norte, área que ha recepcionado un $16,2 \%$ de dicha población ${ }^{1}$. En efecto, un

\footnotetext{
* Profesor de la Facultad de Ciencias Jurídicas de la Universidad Católica del Norte, Antofagasta. Doctor en Derecho por la Pontificia Universidad Católica de Valparaíso. Máster en Derecho, Empresa y Justicia por la Universidad de Valencia. Correo electrónico: amondaca@ucn.cl, dirección: avenida Angamos 0610, Antofagasta. Este trabajo se inscribe en el proyecto Fondecyt de Iniciación 2015 No 11150118 ("La incidencia de los vínculos de familia en la resolución de las acciones de amparo deducidas para revocar las decisiones administrativas de expulsión de extranjeros").

1 Situación de los DD.HH. en Chile. Informe Anual. INDH (2016), p. 41.
} 
relevante porcentaje de población extranjera se ha radicado en las regiones de Arica y Parinacota, Tarapacá, Antofagasta y Atacama ${ }^{2}$. Lo anterior se explica en razón de la bonanza económica que han reportado al Norte Grande las riquezas provenientes de la actividad minera y los diversos servicios relacionados con ella ${ }^{3}$.

En cuanto a los principales países de origen de los inmigrantes, éstos son Bolivia, Perú y Argentina, es decir, los países con los que limita el extremo norte de Chile. A mayor detalle, la mayor población foránea es la peruana $(31,7 \%)$, seguida de la argentina $(16,3 \%)$, y de la boliviana $(8,8 \%)$. También destacan los colombianos $(6,1 \%)$ y los ecuatorianos $(4,7 \%)^{4}$.

El aludido aumento de inmigrantes ha provocado un alza en las órdenes de expulsión de los mismos, emitidas por la autoridad administrativa en ejercicio de sus facultades discrecionales. En efecto, la normativa de extranjería, constituida, en esencia, por el decreto ley No 1.094 de 1975, Ley de Extranjería, y por el decreto supremo 597 de 1984, Reglamento de Extranjería, entrega a la prudencia del órgano administrativo la decisión relativa a la expulsión de los inmigrantes. En particular resalta el artículo 13 del Reglamento de Extranjería, en cuya virtud, con relación a las facultades mencionadas, prescribe que: "estas atribuciones serán ejercidas discrecionalmente, atendiéndose, en especial, a la conveniencia o utilidad que reporta al país la concesión de estos permisos, y a la reciprocidad internacional, previo informe, cuando corresponda, de Policía de Investigaciones de Chile".

Teniendo presente lo señalado, los extranjeros han buscado los instrumentos jurídicos que les permitan revocar, en sede judicial, la medida que los amenaza. De esta manera, han deducido acciones de amparo en virtud de las cuales se califica de "arbitrario" el respectivo acto administrativo, debido a que incidiría negativamente en los vínculos de familia que han constituido y se afectaría su libertad personal. En apoyo de sus alegaciones, se ha citado una serie de normas, tanto internacionales como de derecho interno, relativas a la protección de la familia. Especialmente, a propósito de las normas internacionales, se ha invocado la consideración principal que debe otorgarse al interés superior del niño, según el inciso $1^{\circ}$ del artículo 13 de la Convención sobre los Derechos del Niño5. Con relación

2 Tessada (2013), p. 2.

3 TAPIA (2012), p. 177.

4 Informe OBIMID. La migración en Chile (2016), p. 41.

5 Entre otros tratados y convenciones, se ha acudido a la Declaración Universal de los DDHH, dado que su artículo 16 reconoce el derecho a "fundar una familia". Por su parte, el Pacto Internacional de Derechos Económicos, Sociales y Culturales establece en el artículo 10.1: "Se debe conceder a la familia, que es el 
al derecho chileno, se ha señalado que de acuerdo al inciso $2^{\circ}$ del artículo $1^{\circ}$ de la Constitución Política, "La familia es el núcleo fundamental de la sociedad", y que, en conformidad a lo establecido en el inciso final del mismo artículo, es un deber del Estado proteger a la familia y propender a su fortalecimiento ${ }^{6}$.

Sobre lo último se centra el presente trabajo, esto es, estudiaremos la entidad que las Cortes de Apelaciones (en adelante "CA") del Norte Grande han atribuido al matrimonio, a las uniones de hecho y a la filiación, a fin de revocar las órdenes de expulsión de inmigrantes ${ }^{7}$.

\section{EL RECONOCIMIENTO A LA RELEVANCIA QUE POSEEN LOS VÍNCULOS DE FAMILIA}

Analizaremos, a continuación, la relevancia de primer orden que los tribunales objeto del presente trabajo han concedido a los vínculos de familia que han constituido los inmigrantes. De esta manera, en los últimos años se ha podido apreciar que a los nexos familiares, esto es, matrimonio, uniones de hecho y filiación ${ }^{8}$, sean de origen o constituidos en Chile ${ }^{9}$, se les ha otorgado tal entidad que pueden por sí solos justificar la revocación de las órdenes administrativas de expulsión ${ }^{10}$.

elemento natural y fundamental de la sociedad, la más amplia protección y asistencia posibles, especialmente para su constitución y mientras sea responsable del cuidado y la educación de los hijos a su cargo".

6 Consideremos que el No 2 del artículo 19 de nuestra Constitución consagra la igualdad ante la ley; en consecuencia, la tutela que el ordenamiento jurídico debe proporcionar a la familia debe aplicarse con independencia de la nacionalidad de sus miembros. También se han fundamentado las acciones de amparo en normas de rango legal. Así, se ha hecho presente que el artículo $1^{\circ}$ de la ley No 19.947, Nueva Ley de Matrimonio Civil, en la primera parte de su inciso $1^{\circ}$, reitera el texto constitucional al prescribir que "La familia es el núcleo fundamental de la sociedad", para luego precisar que "El matrimonio es la base principal de la familia".

7 Todas las sentencias mencionadas en el presente trabajo pueden encontrase en la página web del Poder Judicial de Chile: www.pjud.cl.

8 La CA de Iquique, en la sentencia rol No 156-2015, reconoció la importancia del parentesco en la línea ascendente, ya que el amparado vivía en Chile con su madre, quien poseía visación definitiva. Esta Corte también admitió la relevancia del parentesco en la línea colateral (hermana y sobrina del recurrente), en la sentencia rol No 58-2015. En la sentencia rol No 10-2015, también el nombrado tribunal otorgó un papel decisivo al hecho de tener el amparado un hermano residente en Chile. En otro caso, la CA de Iquique estimó, para efectos de acoger una acción de amparo, el hecho que un primo del amparado viviese en Chile, rol No 45-2016. Además, también se ha considerado la relevancia de la descendencia en la línea recta en $2^{\circ}$ grado, es decir, de los nietos; en este sentido se pronunció la CA de Antofagasta en la sentencia rol No 67-2015.

9 Así se declaró en el considerando $5^{\circ}$ de la sentencia rol No 7-2016 de la CA de Iquique, al aludir al perjuicio consistente en la "separación de su grupo familiar, que si bien no es de origen; existe y debe protegerse".

10 La Corte Suprema ha ratificado este criterio en diversas oportunidades. A mayor detalle, consúltese las siguientes sentencias. A propósito del matrimonio: roles $\mathrm{No}_{\text {s. }}$ 6414-2016 y 10190-2017; con relación a las 
Esta evolución es positiva; con anterioridad a ella, podían encontrarse sentencias que no otorgaban relevancia primordial a los nexos de familia. En este sentido, en el considerando $5^{\circ}$ de la sentencia de la CA de Iquique, rol No 98-2912, caratulada "Araníbar Viza y otro con Intendencia Regional de Tarapacá", se indicó que: "Por otro lado, el núcleo familiar de la amparada está restringido a su hija y el padre de la nińa con quien aparentemente viviría, lo que excluye a sus padres y hermanos por constituir familia extensa, y, en cuanto a los primeros, no consta que la autoridad administrativa pretenda separarlos si, como se dijo, sabiendo que está en el país ilegalmente, nada ha realizado para hacer efectiva la sanción, sólo ha obrado movido por el afán de hacer cumplir la legislación chilena sobre la materia. Entender lo contrario significaría efectuar una discriminación positiva a su respecto, en desmedro de todos los otros inmigrantes que estuvieren en el país obedeciéndolas".

Incluso, en ocasiones se confirmaba la expulsión, sin siquiera hacerse cargo el tribunal de la alegación de algún nexo de familia, como sucedió en la causa "Tapia Cueto con Intendencia Regional de Antofagasta", de la CA de Antofagasta, rol No 6-2012. En este caso, la recurrente, además de haber vivido dieciséis años en Chile, mantenía una relación de concubinato con un ciudadano chileno, era madre de un menor de nacionalidad chilena, a lo que se sumaban dos hijos peruanos ${ }^{11}$.

\section{La justificación de la autoridad administrativa: el ejercicio de facultades discrecionales}

El descrito escenario ha generado una reacción por parte de la autoridad administriva. Una usual defensa del ente administrativo ha sido alegar que la decisión de expulsión se encuentra entregada a su discrecionalidad por parte del legislador. Es decir, se trata de una defensa basada en la mera atribución expresa de competencias; de esta manera, mal podría calificarse como "arbitraria" una

uniones de hecho, roles: 981-2011, 7018-2012, 66-2013, 10769-2013, 6366-2013, 6649-2013, 9081-2014, 10836-2014, 9051-2015, 12356-2015 y 17127-2016; y sobre la filiación, roles: 3867-2010, 981-2011, 7018-2012, 1805-2013, 2174-2013, 66-2013, 4463-2013, 6366-2013, 6649-2013, 4466-2013, 10769 2013, 9081-2014, 9098-2014, 10836-2014, 3574-2015, 9051-2015, 12356-2015, 8397-2017, 4964-2017, 9386-17 y $9317-2017$.

11 En idéntico sentido se pronunció la sentencia de la CA de Antofagasta rol No 45-2014. En efecto, en esta causa también se alegó la existencia de una unión de hecho y la generación de descendencia. El motivo de expulsión fue la comisión del delito de tráfico de drogas. Véase, también, la causa rol No 51-2015 de la CA de Antofagasta. 
resolución que ordena el abandono forzado de un extranjero, puesto que aquélla sería una manifestación de un ejercicio de atribuciones legales ${ }^{12}$.

Lo anterior puede apreciarse en el considerando $2^{\circ}$ de la sentencia de la CA de Copiapó "Lina Grajales Vélez con Intendencia Regional de Atacama", rol No 341-2015, al indicarse que "a fojas 70 rola informe evacuado por el señor intendente de la Región de Atacama, quien peticiona el rechazo del presente arbitrio, por improcedente e inadmisible, pues la orden de expulsión cuestionada se ha dictado en uso de sus facultades, contenidas en el artículo 69 del D.L. No 1094 de 1975, que establece normas sobre extranjeros en Chile, habiéndose tomado razón por la Contraloría Regional de Atacama respecto de la indicada resolución. En consecuencia, concluye, la misma se ha dictado por autoridad competente, dentro del imperio de sus facultades, las que le han sido delegadas por el decreto supremo No 818 de 13 de julio de 1983".

Similar sendero recorrió la CA de Copiapó en la causa "Aguasvivas con Intendencia Regional de Atacama”, rol No 355-2013, dado que en el considerando $3^{\circ}$ de la sentencia se estableció: "Que apareciendo de los antecedentes que la orden de expulsión del territorio nacional cuestionada ha sido dispuesta por autoridad facultada por la ley al efecto, por lo que ningún reproche puede efectuarse a la eventual restricción a la libertad ambulatoria que esta decisión pudiere irrogar a la amparada, forzoso resulta desestimar la presente acción cautelar"13. Como podemos apreciar, es lamentable constatar que, en ocasiones, con el solo mérito de la atribuciones de competencias a favor de la autoridad administrativa, realizada por el legislador, se ha descartado la eventual arbitrariedad de la decisión adoptada ${ }^{14}$.

El argumento en análisis ha sido rechazado en reiteradas ocasiones, concediendo los sentenciadores preponderancia a los vínculos de familia, los que deben ser debidamente apreciados y no pueden ser conculcados sobre la base de un ejercicio discrecional de facultades. En este sentido se pronunció la CA de Antofagasta, en sentencia rol No 16-2016, en el caso "Cortés Blandón con Intendencia Regional de Antofagasta", al establecer en su considerando $1^{\circ}$ que: "aunque las autoridades de extranjería y migración se arroguen facultades que tienen como fuente formal la ley, éstas no son imperativas, sino facultativas, y el actuar de los agentes del Estado debe respetar el principio de supremacía constitucional, y tomar en

12 CA de Antofagasta, sentencia rol No 86-2016.

13 Idéntico criterio se adoptó por la CA de Arica, en sentencia rol No 45-2013.

14 Véase, también, sentencia de la CA de Copiapó, rol No 328-2015. 
cuenta todas y cada una de las consideraciones a la hora de aplicar una sanción tan gravosa como la expulsión de un extranjero de Chile".

En suma, como lo declaró la CA de Iquique, no basta con un "control de mera legalidad de lo actuado en cuanto afecte la libertad personal y la seguridad individual", considerando $4^{\circ}$ de la sentencia rol No 42-2016, "Ramírez Flores con Intendencia Regional de Tarapacá"15.

\section{La protección otorgada a los nexos de familia, en el marco de las acciones de amparo}

Con relación al matrimonio, en el caso "Grillo Henao con Gobernación Provincial de Antofagasta”, rol No 67-2015, la CA de Antofagasta, en el considerando $6^{\circ}$, justificó su decisión de revocar la expulsión, entre otros aspectos, en la tutela del matrimonio, no obstante la comisión en el país de origen del inmigrante (Colombia) del delito de tráfico, fabricación o porte de estupefaciente. Así, en el mencionado considerando se indicó que: "en todo caso, sobre la base del principio de la buena fe, debe entenderse (...) que contrajo matrimonio en agosto del presente año, lo que significa que hay un núcleo familiar formado que, de acuerdo al artículo $1^{\circ}$ de la Constitución Política de la República, es fundamental en la sociedad, a todo lo cual debe agregarse que el antecedente criminal es de larga data y que, conforme a la legislación nacional, especialmente al artículo 104 del Código Penal y ley No 18.216, hoy no puede ser considerado, de manera que careciendo de argumentos la resolución exenta No 15.344, se torna arbitrario en cuanto a disponerse el abandono del país" 16 .

Más nutrida es la jurisprudencia existente a propósito de las uniones de hecho. En este sentido, la CA de Arica, en la causa rol No 72-2017, caratulada "Pérez Quevedo con Intendencia Regional de Arica y Parinacota", en atención a la existencia de un concubinato del que formaba parte el recurrente, revocó la orden de expulsión, indicando en el considerando $8^{\circ}$ que el amparado ha "formado su

15 La CA de Iquique, en la sentencia rol No 36-2016, en su considerando 4º, calificó de arbitraria una supuesta fundamentación de un acto administrativo consistente en la cita de diversas normas legales: "Por otra parte, la justificación del rechazo a la solicitud de reconsideración del decreto de expulsión por parte de la recurrida se basó en nuevos antecedentes que obran en poder de la Intendencia Regional de Tarapacá. Sin embargo, no se precisa en qué consistirían aquellos nuevos antecedentes, limitándose a citar una serie de artículos de la normativa sobre extranjería, sin que se hubiese aportado razón alguna que permita entender y convencer, a quien tome conocimiento de la resolución, las motivaciones que condujeron a su adopción".

16 Consúltese, además, las sentencias de la CA de Iquique roles $\mathrm{No}_{\text {s. }}$ 145-2015, 128-2015 y 9-2014. 
núcleo familiar en Chile, y de esta forma, una ya pretérita resolución de grave trascendencia, emanada de una autoridad administrativa, obligará al amparado a dejar lo que hoy es su familia, lo que implica un menoscabo no sólo a su libertad de desplazamiento, sino que también a la integridad de la familia". La CA de Iquique también reconoció la entidad de las uniones de hecho en la causa "Rodríguez Potter con Intendencia Regional de Tarapacá", rol No 128-2016, al sostener en el considerando 7o: "Que, finalmente, es un hecho indiscutido que han variado las circunstancias personales que tuvo a la vista la Intendencia Regional al momento de decretar la expulsión de la amparada. En este contexto, adquiere especial importancia el hecho de que el recurrente (...) mantenga una relación sentimental con un ciudadano chileno, que no tenga antecedentes criminales y que cuente con un contrato de trabajo sujeto a la condición de obtener la visación correspondiente. De este modo, se ha demostrado por parte de la interesada la existencia de vínculos en nuestro país".

Interesante es la sentencia de la CA de Iquique, rol No 73-2015, recaída en la causa caratulada "Montoya con Policía de Investigaciones de Chile e Intendencia Regional de Tarapacá", dado que en ella se tutela una relación de hecho, pero de la cual la amparada no formaba parte, sino que el ingreso ilegal de la inmigrante se produjo, una vez que le fue negada la entrada a Chile por las autoridades correspondientes, para otorgar cuidados médicos a la concubina de su tío, dado que no existían más parientes de la enferma en territorio nacional. En otras palabras, como se expresó en el considerando $2^{\circ}$, en concepto del recurrente, podría entenderse que "la amenaza de inminente expulsión atentaría contra la familia como núcleo fundamental de la sociedad y no repara en las razones humanitarias esgrimidas".

Con todo, no se revocó la medida de expulsión, puesto que, según se expresó en el considerando $3^{\circ}$, aunque "debe atenderse a las circunstancias personales y familiares de la reclamante - por cuanto la familia es el núcleo fundamental de la sociedad, y es deber del Estado dar protección a la población y a la familia, así como propender al fortalecimiento de ésta- lo cierto es que la recurrente no proporciona ningún antecedente fáctico en sustento de sus alegaciones, que otorgue plausibilidad a la supuesta enfermedad de una familiar respecto de la cual tampoco acredita el vínculo de parentesco que la une".

Centrándonos en la parte del considerando recientemente transcrito vinculada a los nexos de familia, uno de los motivos del rechazo de la acción de amparo fue que no se probó en forma debida el vínculo de parentesco con la pareja de su tío, que sufría de una enfermedad. Lo último nos llama la atención, porque, con estricto apego a nuestro derecho de familia, en principio, no existe parentesco 
alguno entre el concubino(a) con los consanguíneos de su pareja. Lo afirmado debe ser precisado a la luz de la regulación del acuerdo de unión civil efectuada por la ley No 28.830, publicada en el Diario Oficial de fecha 21 de abril de 2015, pero que entró en vigencia seis meses después de su publicación en el mismo, en conformidad a lo dispuesto en el artículo $1^{\circ}$ transitorio del nombrado texto legal. La fecha de la sentencia en comento es 30 de abril de 2015, es decir, todavía no comenzaba la vigencia de la ley No 28.830. El artículo $4^{\circ}$ de dicho cuerpo legal establece que existe parentesco por afinidad, durante la vigencia del contrato, entre el conviviente civil y los consanguíneos de la persona con la que está unida por un acuerdo de unión civil. Agrega la parte final del citado artículo: "La línea y grado de afinidad de una persona con un consanguíneo de su conviviente civil se califica por la línea o grado de consanguinidad de dicho conviviente civil". Es decir, la mencionada ausencia de parentesco a que hemos aludido no sufre alteración en el caso que comentamos con la disciplina del acuerdo de unión civil.

Distinto, con la normativa actualmente vigente, hubiese sido la situación de la amparada de haber celebrado un acuerdo de unión civil su tío con su pareja, dado que en dicho escenario, según la norma transcrita, sí se hubiese generado un parentesco por afinidad entre la conviviente civil que estaba enferma con los consanguíneos del otro contratante, esto es, con la amparada ${ }^{17}$.

La filiación también ha permitido acoger las acciones de amparo que estudiamos. La CA de Iquique, en el caso "Moreno Villa con Intendencia Regional de Tarapacá", resuelto por la sentencia rol No 27-2017, en el considerando $4^{\circ}$ estableció que "es un hecho indiscutido que han variado las circunstancias personales y familiares que tuvo a la vista la Intendencia Regional al momento de decretar la expulsión del amparado. En este contexto, adquiere especial importancia el hecho que la recurrente mantiene una relación con un ciudadano dominicano con residencia temporaria en el país y que tiene un hijo por nacer que tendrá la nacionalidad chilena, además de demostrar que ha logrado obtener una fuente laboral y no registra antecedentes penales. De este modo, se ha demostrado por parte de la interesada la existencia de vínculos en nuestro país". Se agregó en el considerando $5^{\circ}$ "Que en esa línea, en relación a la aplicación de las normas de

17 Sobre este vínculo de familia, también, véase: CA de Arica, sentencias roles: 151-2015 y 129-2015; CA de Iquique, sentencias roles: 19-2017, 132-2016, 128-2016, 123-2016, 122-2016, 115-2016, 94-2016, 85-2016, 71-2016, 66-2016, 64-2016, 60-2016, 58-2016, 47-2016, 45-2016, 42-2016, 34-2016, 131 2015, 129-2015, 100-2015, 35-2015, 133-2014, 130-2014 y 92-2014; CA de Antofagasta, sentencias roles: $46-2016,8-2016,6-2015$ y $16-2013$. 
extranjería, es importante atender a las circunstancias personales y familiares de la reclamante, puesto que su salida involuntaria del país traería inevitables consecuencias, como la separación de la recurrente y su grupo familiar, en especial de su hijo por nacer. Las señaladas circunstancias deben tener preponderancia sobre las disposiciones migratorias utilizadas por la intendencia para imponer la sanción administrativa de expulsión"18.

Es decir, deben evitarse los cambios que puedan afectar el desarrollo de los menores ${ }^{19}$. En esta línea, la CA de Iquique resolvió que "adquiere especial importancia el hecho que los recurrentes tengan dos hijos de nacionalidad chilena y que sus hijos de origen colombiano fueran autorizados por la autoridad educacional de la Región de Antofagasta para cursar sus estudios en establecimientos de su dependencia, adjuntándose los respectivos certificados de alumno regular, antecedentes que denotan la existencia de vínculos en nuestro país por parte de la familia de los actores, atendida la larga data que llevan residiendo el país", causa "Landázuri Castillo con Intendencia Regional de Antofagasta", considerando $7^{\circ}$ de la sentencia rol No 107-2016. También es relevante la sentencia de la CA de Antofagasta "Osorio Minaya con Intendencia Regional de Antofagasta", rol No 65-2015, en la que, considerando la enfermedad del hijo de la amparada, se revocó la medida de expulsión, aplicando los artículos 7.1 y 9.1 de la Convención sobre los Derechos del Niño. Esta sentencia reconoció el derecho de los menores de edad de conocer a sus padres y "de ser cuidados por ellos", como expresamente se consignó en el considerando $8^{\circ}$ del referido fallo.

A propósito de la filiación, además, se ha reconocido que, en caso de embarazo de la mujer inmigrante ${ }^{20}$, podrían producirse lesiones tanto a la salud de ésta

\footnotetext{
18 A idéntica conclusión arribó la CA de Arica, teniendo en vista que la amparada tenía dos hijas y una pareja. En efecto, puede leerse en el considerando 5० de la sentencia rol No 56-2017 "Que, en este contexto, adquiere especial importancia el hecho de que la recurrente ha formado una familia en el país, y se ha demostrado por parte de la interesada la existencia de vínculos familiares sólidos en nuestro país, de manera que en relación a la aplicación de las normas de extranjería, resulta importante atender a ellas, puesto que su salida involuntaria del país traería inevitables consecuencias, como la separación de su grupo familiar, que debe protegerse, tratándose de circunstancias que deben tener preponderancia sobre las disposiciones migratorias utilizadas para imponer la sanción administrativa de expulsión".

19 Véase Barrientos (2012), pp. 117-126.

20 CA de Arica, rol No 56-2017. A propósito del embarazo, consúltese, además, del mismo tribunal, las sentencias roles $\mathrm{N}^{\circ}$ s. 129-2015 y 120-2015 y la sentencia de la CA de Antofagasta rol No 16-2016.
} 
como a la de la criatura que lleva en el vientre ${ }^{21}$. Finalmente, el estado de salud del niño ha contribuido a revocar las órdenes de expulsión, como la consideración de una fisura de labio palatina unilateral, la que requería de cuidados médicos especializados y prolongados 22 .

\section{La exigencia de la prueba del vinculo de familia $y$ de un auténtico arraigo social del inmigrante}

Establecida la importancia de valorar la situación familiar del amparado, debemos introducir en el análisis una nueva consideración: no es suficiente con una mención y acreditación de la existencia jurídica de algún vínculo de familia, es necesario, además, que dichos vínculos se concreten en la sociedad. Es decir, el onus probandi debe soportarse en un doble sentido: en primer lugar, con respecto a la presencia misma de un nexo de familia, y, en segundo término, a propósito de su traducción en la realidad ${ }^{23}$.

Con respecto a la prueba, existen varios casos en que los inmigrantes han alegado la tutela de vínculos de familia, pero las acciones de amparo que han deducido se han rechazado en atención a la falta de acreditación de la existencia de los nexos familiares invocados.

En la sentencia rol No 9-2016 de la CA de Iquique, "Muñoz Cifuentes con Intendencia Regional de Tarapacá y Policía de Investigaciones de Chile", se confirmó la expulsión al no acreditarse suficientemente el vínculo de familia alegado. Se invocó un concubinato, el que se pretendió acreditar con una declaración jurada notarial, medio probatorio que no permitió formar la convicción del sentenciador. Como ya hemos indicado al tratar de las uniones de hecho, el nombrado tribunal rechazó una acción de amparo, entre otros motivos, al no probarse la supuesta enfermedad de la hermana de la pareja de su tío, sentencia rol No 141-2015, "Montoya con Policía de Investigaciones de Chile e Intendencia Regional de Tarapacá".

\footnotetext{
21 Revísese, además, sobre la relevancia otorgada a la filiación: CA de Arica, sentencias roles: 56-2017, 151-2015 y 129-2015; CA de Iquique, sentencias roles: 19-2017, 132-2016, 107-2016, 128-2016, 122 2016, 85-2016, 62-2016, 58-2016, 48-2016, 46-2016, 34-2016, 142-2015, 131-2015, 35-2015, 7-2015 y 9-2014; CA de Antofagasta, sentencias roles: 67-2017, 8-2016; 6-2015; 22-2014 y 16-2013; y CA de Copiapó, sentencia rol No 341-2015.

22 CA de Antofagasta, causa rol No 65-2015.

23 Consúltese Mondaca (2011), pp. 41-54, y Audit (2000), p. 547.
} 
Otro caso llamativo es el resuelto por la sentencia rol No 24-2015 de la CA de Iquique, "Lozano Rivero con Intendencia Regional de Tarapacá", según se indicó en el considerando $6^{\circ}$ : "Por otra parte y en cuanto a la situación personal del recurrente, el amparado no logra fundamentar debidamente la existencia de arraigo en este país, atendido el hecho de que en el texto de su recurso y en su declaración ante funcionarios policiales al momento de ser detenido, invoca como motivo fundante del ingreso, su intención de continuar su relación con una mujer de nombre Erika María Salazar, pero se acompaña un documento respecto a una persona distinta, a saber Luz Rodallega Lozano, alegando al final de su libelo, que ella sería su pareja, sin dar mayores explicaciones a esta contradicción, lo que en definitiva resta credibilidad a este fundamento".

La falta de prueba también fue clave para la CA de Iquique en la causa rol No 60-2013, "Ramos Portillo con Intendencia Regional de Tarapacá"; en este sentido, en el considerando $2^{\circ}$ se concluyó que: "En sentido inverso, el recurrente no demostró de manera alguna que la amparada se encuentre privada de libertad, que haya tenido una hija con un ciudadano chileno, que vivan juntos y la edad de la niña que sería su hija". En similar sentido, la misma Corte, en la sentencia rol No 58-2015, "Cardona Ojeda con Intendencia Regional de Tarapacá", entendió que no se había acreditado una supuesta relación sentimental del amparado, dado que sólo se acompañaron fotografías que no permitían establecer la autenticidad del vínculo de familia alegado.

Reafirma lo anterior una sentencia de la CA de Iquique, la que confirmó la medida de expulsión respecto de una ciudadana de República Dominicana, en virtud de un ingreso irregular, madre de una hija que vivía en Chile en la ciudad de Salamanca. Decisivo para lo anterior fue la falta de acreditación de un debido vínculo de familia, como se indicó en el considerando $6^{\circ}$ de la sentencia rol No 33-2017, "Payano con Intendencia Regional de Tarapacá": "Finalmente, resulta conveniente explicitar que en la especie no existen antecedentes de hecho que ameritaren una decisión diversa desde que la amparada no ha acreditado, de manera alguna, un interés prevalente de índole familiar, personal o laboral para acoger su pretensión".

A propósito de la exigencia de "arraigo", se ha sentenciado que debe poder apreciarse una auténtica radicación familiar, por lo tanto, social del extranjero ${ }^{24}$.

24 El arraigo religioso fue considerado por la CA de Iquique, en la sentencia rol No 131-2015, a propósito de un ciudadano colombiano condenado por el delito de tráfico de drogas, miembro activo de la Iglesia Evangélica Pentecostal de Pozo Almonte. 
En otras palabras, han exigido acertadamente los tribunales que el vínculo de familia alegado posea un correlato en la realidad, el que deberá ser probado por el inmigrante. En este sentido, la CA de Antofagasta, en el caso "Rojas Pavón con Intendencia Regional de Antofagasta", fallado en la sentencia rol No 86-2016, otorgó tal trascendencia al arraigo social y familiar del inmigrante, que concluyó que éste podía transformar en arbitraria una expulsión fundada en la residencia irregular del extranjero, al haber expirado la correspondiente visa. En efecto, según el considerando $5^{\circ}$ del fallo en análisis, "sin perjuicio de lo anterior, tratándose de un extranjero, que ingresó con visa de turista y no realizó las gestiones necesarias, debe tenerse especial consideración que no se discute o es controvertido que su estadía sin la autorización correspondiente se prorrogó por un tiempo superior a un año y seis meses, lo que inequívocamente demuestra una arraigo familiar y social, lo que un mero decreto de expulsión sin fundamento, se torna arbitrario desde que proviene de la sola voluntad de la autoridad sin que tenga una fundamentación racional y legal".

Otro caso interesante es el caratulado "Bazalar Koro con Intendencia de la Región de Arica y Parinacota", resuelto en la sentencia de la CA de Arica, rol No 77-2016, en la que se rechazó la acción de amparo, no obstante la presencia de vínculos de familia. En este sentido, se estableció en el considerando $6^{\circ}$ "Que, la situación familiar invocada, no es un elemento que pueda importar una entidad tal, que sea capaz de tornar en ilegal la decisión adoptada, particularmente cuando la sola circunstancia de ser abuela de una nieta nacida en Chile y que reside en otra ciudad distante de aquella en que reside la recurrente cuyo padre (hijo de la recurrente) no registra residencia legal en el país, a lo que se suma la existencia de dos hijos que residen en el Perú, no acreditan la real y efectiva existencia de vínculos familiares, razón por la cual el decreto de expulsión no se avizora que vulnere el deber de protección del Estado respecto de la familia, puesto que aquello no es un elemento que permita soslayar con ligereza el cumplimiento de los deberes legales que pesan sobre el migrante, quien claramente ha quebrantado el régimen legal vigente en Chile".

Mismo razonamiento se encuentra en la sentencia de la CA de Antofagasta rol No 1-2016, "Parra Velásquez con Gobernación Provincial de Antofagasta y Departamento de Extranjería y Migración”, que confirmó la expulsión de una ciudadana colombiana, que se había casado con un chileno en Colombia, porque sólo se acompañó un certificado de matrimonio, sin aportar mayores antecedentes.

Es decir, los tribunales han considerado los "proyectos de vida" de los extranjeros, tal como resolvió la CA de Iquique a propósito de un ciudadano boliviano 
que llevaba treinta años viviendo en Chile, que tenía cuatro hijos y que, incluso, había accedido a beneficios sociales ${ }^{25}$. En suma, para efectos de resolver los litigios de extranjería que comentamos, un factor decisivo ha sido la existencia o ausencia de un auténtico arraigo familiar del amparado. Así, en los casos en que se ha acreditado dicho arraigo, se ha procedido a revocar la medida de expulsión ${ }^{26}$. Por el contrario, de no probarse lo anterior, no se han acogido las acciones de amparo, es decir, se confirma el abandono forzado del territorio nacional por parte del extranjero que no ha acreditado arraigo en nuestra sociedad ${ }^{27}$.

En suma, del análisis de las sentencias mencionadas queda claro que los vínculos de familia se han convertido en un elemento de primer orden, llegado el

25 El motivo de la expulsión fue la residencia iregular, sentencia rol No 36- 2017.

26 Véanse las siguientes sentencias: CA de Arica, rol No 86-2016; CA de Iquique, roles Nos. 19-2017, 107-2016, 66-2016, 47-2016, y CA de Antofagasta, rol No 86-2016.

27 Revísense las siguientes sentencias: CA de Arica, roles: 283-2016, 224-2016, 158-2016 y 84-2016; CA de

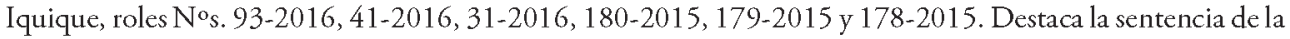
CA de Iquique rol No 1-2016, en que la falta de arraigo resultó un factor decisivo, en efecto, se estableció en el considerando 6: "Finalmente, resulta procedente, explicitar que la amparada, no ha justificado de manera alguna, un interés prevalente para acoger su pretensión, ello, en cuanto no ha demostrado sus medios de vida en este país, además que en su relato y documentación, se evidencian contradicciones, dado que concurre a una oficina en Santiago para efectos de interponer el recurso, fijando domicilio en la misma, pero acompańa un contrato a futuro donde figura como empleador una persona domiciliada en Iquique, y, además, en su carta de fojas 8 , indica como domicilio un local comercial, nuevamente en Iquique, figurando allí que tendría una promesa de trabajo emanada de una persona distinta a quien suscribe el contrato acompańado; con lo que se evidencia que carece de arraigo suficiente, sin que pueda estimarse válido para estos efectos, el citado contrato a futuro, por revestir caracteres de mera oferta para el evento que regularice su situación en el pais". La misma CA, en la sentencia rol No 164-2015, en el considerando 6º, determinó que la realización de trabajos esporádicos y el hecho que la familia del amparado no residiese en Chile, no permitían acreditar un arraigo suficente. Siempre según la CA de Iquique, en la sentencia rol No 49-2015, se confirmó la expulsión, no obstante alegar el amparado que desempeńaba el oficio de zapatero en su país de origen, lo que no configuraría arraigo en Chile. El mismo tribunal, en el considerando $5^{\circ}$ de la sentencia rol No 15 2014, concluyó: "Que en cuanto a la protección constitucional de la familia como núcleo fundamental de la sociedad y el interés superior del niño, cabe consignar que el recurrente sólo acompańó los certificados de nacimiento de sus hijos, de 2 y 4 ańos de edad, sin otro antecedente que compruebe un efectivo arraigo familiar, pues nada consta en cuanto a que los nińos se encuentran bajo su cuidado o en cuanto a que su sustento dependiere de él, así como tampoco consta que mantenga convivencia con la madre de los menores". A igual conclusión llegó la CA de Arica, en la causa rol No 282-2016, en el considerando $5^{\circ}$ de la sentencia, a propósito de la alegación de vivir el amparado con su hermano, se señaló que "la situación familiar y laboral invocada, no es un elemento que pueda importar una entidad tal, que sea capaz de tornar en ilegal la decisión adoptada, en tanto no acredita la real y efectiva existencia de vínculos familiares ni determina que por el decreto de expulsión se vulnere el deber de protección del Estado respecto de la familia, ni sea éste un elemento que permita soslayar con ligereza el cumplimiento de los deberes legales que pesan sobre el migrante, quien claramente ha quebrantado el régimen legal vigente en Chile". 
momento de decidir en sede judicial sobre la mantención o revocación de una medida que ordena la expulsión de un extranjero. Incluso, pueden encontrarse sentencias que han revocado expulsiones en las que se realiza una mención genérica a los vínculos de familia y a la afectación que en éstos produciría la ejecución de la expulsión, sin siquiera individualizar los nexos familiares que en la especie han concurrido. Lo anterior sucedió en la sentencia de la CA de Antofagasta rol No 86-2016, "Rojas Pavón con Intendencia Regional de Antofagasta", y en la sentencia rol No 63-2016 de la CA de Iquique, "Ruiz Pérez con Intendencia Regional de Tarapacá".

Esta entidad atribuida por la jurisprudencia a los vínculos de familia también ha sido advertida por la autoridad administrativa. Así, llama la atención que uno de los diversos fundamentos de sus medidas de expulsión sea la ausencia de un nexo de familia, como se hizo presente en el considerando $2^{\circ}$ de la sentencia de la CA de Antofagasta rol No 86-2016, ya individualizada previamente ${ }^{28}$.

\section{LA APLICACIÓN DEL PRINCIPIO DE PROPORCIONALIDAD DE LAS SANCIONES}

Hemos dicho que consideramos un acierto la interpretación que conduce a conceder a los nexos de familia un rol decisivo en los juicios de extranjería. Con todo, lo anterior no significa transformar tales nexos en obstáculos insalvables para efectos de expulsar a un extranjero que ha cometido infracciones particularmente repudiables. De otra manera, bastaría con alegar y probar un arraigo familiar para que un inmigrante, no obstante la perpetración de una serie de ilícitos, pudiese evitar la aplicación de la respectiva normativa de extranjería.

Lo señalado fue considerado por la CA de Antofagasta en la sentencia rol No 6-2015, "Omoregie con Intendencia Regional de Antofagasta", en su considerando $3^{\circ}$, al fallar que: "En cuanto a la alegación de que la expulsión afectaría a los menores hijos del amparado, cita jurisprudencia de esta Iltma. Corte, en tanto la existencia de hijos no puede constituir una causal de exculpación o justificación para el quebrantamiento de la norma, lo que fue confirmado por la Excma. Corte Suprema”. En efecto, el extranjero expulsado había cometido una serie de ilícitos, por lo que concluyó el sentenciador, en el considerando $5^{\circ}$, que "la comisión reiterada de delitos de diversa naturaleza, a lo que debe añadirse su permanencia irregular en el país, da cuenta que la decisión de la autoridad admi-

28 A mayor detalle, en la parte pertinente del citado considerando se precisó que el inmigrante "no contaba con un vínculo con ciudadano chileno o extranjero en Chile". 
nistrativa competente para pronunciarse a este respecto, resulta fundada, dentro de la esfera de sus atribuciones, concurriendo una causal de aquellas previstas en la ley, por lo que en caso alguno puede predicarse que su decisión resulte contraria a la Constitución Política de la República o ilegal, por lo que procede rechazar la presente acción"29.

Por exigencias derivadas de la lógica y de la justicia, no resulta adecuado dejar sin sanción a quien ha violado la normativa del país que le ha acogido. Lo anterior podría parecer contradictorio. En efecto, por una parte afirmamos que deben protegerse los vínculos de familia de los extranjeros, pero, por la otra, entendemos que deben sancionarse los ilícitos que se cometan. Armonizar estos dos intereses es una labor ardua.

Ejemplifica la dificultad de la tarea señalada el caso "Vélez Velásquez y otro con Intendencia Regional de Antofagasta", en que las causales de expulsión fueron la residencia irregular, en virtud de la expiración de la visa correspondiente, y el posterior ingreso clandestino al país, pero el amparado era padre de un niño. Así, la CA de Antofagasta en el considerando $6^{\circ}$ de la sentencia rol No 22-2014, concluyó: "Que no altera lo anterior, la circunstancia que la amparada haya tenido una hija en nuestro país. La pretensión de dejar sin efecto el decreto de expulsión fundado en los efectos negativos que aquél pudiera tener para la niña no puede ser acogida, como quiera que la determinación constituye una sanción por el quebrantamiento grave de la normativa de extranjería y la circunstancia de ser madre de un infante no puede constituir una causa de exculpación ni menos un motivo que justifique la omisión en la sanción del ilícito. Por lo demás, se mantiene incólume los derechos y obligaciones de la madre con relación a su hija”. Según lo establecido en este trabajo, lo decidido por la CA de Antofagasta es discutible.

Esta dificultad y aparente contradicción ha sido resuelta por los tribunales de justicia aplicando el principio de proporcionalidad de las sanciones en sentido estricto. Como lo señalan Arnold, Martínez y Zúñiga, "la gravedad de la

29 Los ilícitos en que incurrió el expulsado fueron los siguientes: ingreso ilegal utilizando un pasaporte holandés adulterado, motivo por el que fue expulsado del país el 2 de septiembre de 1999, revocándose el 6 de diciembre de 2005 la resolución de expulsión otorgándosele un plazo de 10 días para que regularizase su situación, lo que nunca aconteció; condena por uso malicioso de instrumento mercantil falso en el año 2008; condena por estafa en el mismo ańo, por ambos delitos se le concedió el beneficio de remisión condicional de la pena, pero la decretada medida cautelar de firma dejó de ser cumplida a partir del 25 de abril de 2014, sin justificación alguna; antecedentes policiales (detenciones) por ingresos clandestinos, hurto, estafa, microtráfico, sin cargos formulados en su contra, y una serie de denuncias por infracciones a las normas de extranjería. Hemos comentado esta sentencia en MondaCa (2016), pp. 293-301. 
intervención ha de ser la adecuada al objetivo de la intervención, por tanto los instrumentos y los medios aplicados deben justificarse en su grado de gravedad: la gravedad de las intervenciones debe ser proporcionada a la urgencia o necesidad de los objetivos. Si éstos no son urgentes o no son muy necesarios, los instrumentos utilizados deben ser de menor intensidad" 30 . En virtud de dicho principio, una determinada sanción (por ejemplo, la medida de expulsión) puede ser calificada de arbitraria si de ella se derivan más perjuicios que beneficios ${ }^{31}$.

Aplicando lo anterior a las acciones de amparo que estudiamos, debemos determinar cuál es el beneficio y el perjuicio que eventualmente podrían derivarse de la ejecución de la orden de expulsión. El beneficio sería el abandono forzado de un extranjero que ha violado el ordenamiento jurídico. El perjuicio se concretaría en la falta de tutela al núcleo fundamental de la sociedad. Así, la familia se vería dañada al producirse la disgregación de la misma, se generaría una situación de desarraigo que sufrirán los que deban abandonar el país y podría verse privada la familia de su principal fuente de ingresos. Además, en el caso de existir menores de edad, debe agregarse la lesión al principio del interés superior del niño. En síntesis, es posible que en un caso pueda concluirse que los perjuicios son superiores a los beneficios; en dicho evento, la orden de expulsión puede ser calificada de "arbitraria", en consecuencia, sería procedente su revocación. Como lo ha resuelto la CA de Iquique, "Estos elementos deben tener preponderancia sobre las disposiciones migratorias utilizadas por la intendencia para imponer la sanción administrativa de expulsión", considerando 7 o de la sentencia rol № 128-2016, "Rodríguez Potter con Intendencia de la Región de Tarapacá".

Del análisis de las sentencias que hemos estudiado, podemos concluir que existen diversos tipos de perjuicio cuya relevancia ha sido aceptada por los sentenciadores. En primer lugar, se ha aceptado un daño que nos permitimos calificar de "estrictamente familiar", el que apunta a lo indicado en el párrafo anterior, es decir, la directa afección a un vínculo de familia. Por otra parte, se ha reconocido la entidad de un perjuicio "patrimonial", consistente en la pérdida de la fuente laboral del extranjero, en consecuencia, su núcleo familiar se ve privado de su principal fuente de ingresos. En un caso hemos detectado la admisión de un

30 ARNOLD et al. (2012), p. 71.

31 Existe una copiosa bibliografía, tanto nacional como extranjera, sobre el principio de proporcionalidad de las sanciones. Entre otros, véase: BarnÉs (1994), p. 500; Bermúdez (1996), pp. 275-284, y BoetTiger (2009), pp. 577-596. 
perjuicio "no familiar ni patrimonial", consistente en la lesión a las relaciones de amistad, según pasamos a detallar a continuación.

Considerando el primer tipo de perjuicio indicado, la CA de Arica, en el considerando $3^{\circ}$ de la sentencia rol No 56-2017, caso "Huamán Almonacid con Intendencia de la Región de Arica y Parinacota", resolvió que "adquiere especial importancia el hecho de que la recurrente ha formado una familia en el país, y se ha demostrado por parte de la interesada la existencia de vínculos familiares sólidos en nuestro país, de manera que en relación a la aplicación de las normas de extranjería, resulta importante atender a ellas, puesto que su salida involuntaria del país traería inevitables consecuencias, como la separación de su grupo familiar, que debe protegerse, tratándose de circunstancias que deben tener preponderancia sobre las disposiciones migratorias utilizadas para imponer la sanción administrativa de expulsión".

Tomando en cuenta, además, el perjuicio "patrimonial", la CA de Iquique en la sentencia rol No 21-2017, "Moreno Villa con Intendencia de la Región de Tarapacá", consideró el daño que causaría la expulsión del padre proveedor, tal como se estableció en el considerando 50: "Que en esa línea, en relación a la aplicación de las normas de extranjería, es importante atender a las circunstancias personales y familiares del reclamante, puesto que su salida del país le ha traído inevitables consecuencias, como la pérdida de una fuente laboral para manutención su grupo familiar, el cual reside en Chile. Las señaladas circunstancias deben tener preponderancia sobre las disposiciones migratorias utilizadas por la intendencia para imponer la sanción administrativa de expulsión".

Otras sentencias dan cuenta del perjuicio patrimonial que puede generar la expulsión. Así, nuevamente según la CA de Iquique, un perjuicio que debe tenerse en cuenta es la "pérdida de la fuente laboral" del extranjero; así se señaló en el considerando $5^{\circ}$ de la sentencia rol No 7-2016, "Lozano Rivero con Intendencia de la Región de Tarapacá"32. En el caso "Castro Ramírez con Intendencia de la Región de Tarapacá", en virtud de la pérdida de trabajo, se estimó "la profundización de la precaria situación económica de la recurrente y su grupo familiar", considerando $5^{\circ}$ de la sentencia rol No 181-2015.

Otra manifestación, ampliación si se quiere, de perjuicio pecuniario aceptada ha sido la privación de la fuente de manutención, pero para el grupo familiar que vive en el extranjero. En este sentido se pronunció la sentencia de la CA de

32 Véase sobre este punto, del mismo tribunal, la sentencia rol No 6-2016. 
Iquique, en la causa caratulada "De la Rosa Reyes con Intendencia de la Región de Tarapacá", rol No 101-2015, tutelando, de esta manera, a los hijos de la amparada que vivían en República Dominicana, al igual que la sentencia rol No 1-2015 de la misma Corte, al considerar la necesidad de mantener a la familia de la inmigrante, sus hijos, que vivían en República Dominicana.

Finalmente, con relación al perjuicio "no familiar ni patrimonial", la CA de Iquique, en la causa "Baldera con Intendencia de la Región de Tarapacá", en el considerando $5^{\circ}$ de la sentencia rol No 86-2016, admitió como daño de la ejecución de la medida de expulsión "la pérdida de amistades" que el inmigrante hubiese podido tener en Chile.

Teniendo en cuenta la dificultad que puede implicar la labor de aplicación del principio de proporcionalidad de las sanciones a los juicios en análisis, los propios sentenciadores han considerado los siguientes criterios que permiten facilitar la aludida tarea: la calidad de refugiado ${ }^{33}$; el tiempo de residencia en Chile $^{34}$; realizar una actividad remunerada ${ }^{35}$; la propuesta de un trabajo ${ }^{36}$; no

33 La sentencia de la CA de Arica, rol No 73-2017, que rechazó la acción de amparo interpuesta, contiene en su considerando $5^{\circ}$ una lista de criterios a considerar para efectos de resolver sobre la proporcionalidad de la sanción: "no se ha acreditado que carezca de antecedentes penales en su país, que tenga algún oficio o profesión que le permita independencia económica, que tenga la calidad de refugiado o que su vida corra peligro en su país de origen, ni siquiera ha señalado tener algún familiar, pariente o algún tipo de arraigo en el país, de suerte que a falta de estos antecedentes la decisión adoptada no puede ser estimada ilegal ni menos arbitraria".

34 CA de Iquique, sentencias roles 132-2016, 128-2016 y 115-2016; CA de Antofagasta, sentencias roles: $86-2016,13-2016$ y $60-2016$.

35 CA de Arica, sentencia rol No 72-2017; CA de Iquique, sentencias roles: 27-2017, 19-2017, 128-2016, 94-2016, 86-2016, 85-2016, 72-2016, 67-2016, 66-2016, 63-2016, 62-2016, 48-2016, 47-2016, 7-2016, $181-2015,145-2015,128-2015$ y 15-2014. En la sentencia rol No 9-2016 de la CA de Iquique, como se expresó en el considerando $6^{\circ}$, uno de los motivos del rechazo de la acción de amparo, fue que el amparado no demostró "sus medios de vida en este país". La CA de Iquique rechazó, además, la alegación de desear encontrar un trabajo en la sentencia rol No 49-2015. Este mismo tribunal, en la causa rol No 115-2016, aceptó como criterio relevante el ejercicio esporádico del oficio de asesora de hogar.

36 CA de Iquique, sentencias roles: 132-2016, 128-2016, 86-2016, 71-2016, 66-2016, 60-2016, 6-2016, 164-2015, 129-2015 y 97-2014. Con todo, la sola invocación de este criterio, ha sido considerada insuficiente, CA de Iquique, sentencias roles $\mathrm{N}^{\circ}$ s. 179-2015 y 178-2015. Por el contrario, ańadido a otros criterios, sí ha fundamentado la revocación de expulsiones, como se aprecia en el considerando $4^{\circ}$ de la sentencia rol No 165-2015 de la CA de Iquique, "En este contexto, adquiere especial importancia el hecho que la recurrente es madre de una nińa chilena, de un ańo de edad, que no registra antecedentes penales en su país de origen y que tiene una oferta concreta de trabajo, todo lo cual emana de los instrumentos de fojas 6 a 10 del proceso. De este modo, se ha demostrado por parte de la interesada la existencia de vínculos laborales y de familia en nuestro país". 
haber cometido una infracción diversa de la que motiva la expulsión ${ }^{37}$; presentación de documentos falsos ante la autoridad administrativa ${ }^{38}$; la obtención de beneficios carcelarios en virtud de irreprochable conducta puede revertir la orden de expulsión, como el cumplimiento de la libertad vigilada. Por el contrario, la reincidencia afectaría negativamente al inmigrante, al demostrar que el infractor se ha decidido a continuar en su vida delictiva ${ }^{39}$; ser víctima del delito de trata de personas ${ }^{40}$, y la comisión de ilícitos de particular gravedad ${ }^{41}$, sea en Chile o en el respectivo país de origen ${ }^{42}$.

\section{Conclusiones}

El examen de las sentencias recaídas sobre las acciones de amparo objeto del presente trabajo permite afirmar que en los últimos años, y en diversas ocasiones, nuestra jurisprudencia ha otorgado a los vínculos de familia la debida tutela

37 CA de Iquique, sentencias roles $\mathrm{N}^{\circ}$ s. 27-2017, 132-2016, 128-2016, 86-2016, 66-2016, 62-2016, 7-2016, 6-2016, 156-2015, 131-2015 y 88-2015.

38 En el considerando $4^{\circ}$ de la sentencia de la CA de Antofagasta, rol No 10-2014, se estableció: "Que con el mérito de lo informado no se advierte que la autoridad recurrida haya incurrido en una conducta ilegal o arbitraria al disponer la expulsión de la amparada en la medida que la misma se ha adoptado previa mensura de todos los elementos necesarios para ello, particularmente la gravedad que importa la vulneración flagrante a normas básicas de inmigración como es la presentación de documentos falsos para regularizar su situación. Se trata de la comisión de un hecho de extrema gravedad, por lo cual reproche alguno puede efectuársele a la determinación gubernativa que actuó dentro de la órbita de sus atribuciones".

39 CA de Iquique, sentencia rol No 42-2016. Véase, también, CA de Antofagasta, sentencia rol No 6-2015. En otro caso resuelto por la CA de Antofagasta, rol No 3-2014, no obstante la existencia de matrimonio, la expulsión fue confirmada, puesto que en reiteradas oportunidades el amparado realizó ingresos ilegales al país (había sido expulsado en tres ocasiones).

40 CA de Iquique, rol No 87-2014.

41 Se estableció que el delito de lesiones no poseía la gravedad necesaria para justificar una expulsión, CA de Antofagasta, sentencia rol No 60-2016. Véase, además, CA de Arica, sentencias roles Nos. 69-2017 y 77-2016; CA de Antofagasta, rol No 38-2017. Más riguroso ha sido el criterio cuando se trata del delito de tráfico de drogas. En este sentido, no obstante probarse la existencia de matrimonio y de filiación, se rechazó la acción de amparo, dado que el recurrente de nacionalidad colombiana había sido condenado por tráfico de estupefacientes por el Tribunal de Juicio Oral de Antofagasta, CA de Antofagasta, rol No 45-2016. El indicado criterio también fue aplicado en la causa rol No 46-2016 de la CA de Antofagasta.

42 La sentencia de la CA de Antofagasta, en la causa rol No 34-2014, confirmó la expulsión del amparado que en Colombia había sido condenado por el delito de tráfico, fabricación y porte de estupefacientes. La comisión de un hurto en Colombia motivó el rechazo de la acción de amparo que originó la causa rol No 26-2014, fallada por la CA de Antofagasta. 
exigida, entre otros cuerpos normativos, por nuestra Constitución Política y por distintos tratados y convenciones internacionales.

En efecto, los sentenciadores han entendido que la concurrencia de algún nexo familiar, en forma aislada o copulativa, puede poseer la entidad necesaria para revocar una orden de expulsión de un extranjero. Lo último, siempre que se acredite la existencia y un auténtico correlato social del vínculo invocado, de forma tal de evitar la alegación abusiva del matrimonio, de las uniones de hecho y de la filiación.

Con todo, es necesario que se aplique una sanción respecto de quien ha violado el ordenamiento jurídico. Esta tensión entre la defensa de la familia y el deber de sancionar a los que cometen ilícitos puede ser resuelta acudiendo al principio de proporcionalidad de las sanciones. La sanción de expulsión puede ser desproporcionada si de ella se derivan más perjuicios que beneficios, y pensamos que ello podría suceder en algunos casos de procederse al abandono forzado por parte del extranjero del territorio nacional.

En este sentido, en sede judicial se han establecido diversos tipos de perjuicios generados por la expulsión: el daño que hemos calificado de "estrictamente familiar", concretado en la lesión directa a la familia, al producirse la disgregación de ésta, el perjuicio "patrimonial" consistente en la pérdida de la principal fuente de ingresos del inmigrante y, en consecuencia, de su núcleo familiar, y en un caso se ha reconocido un tercer daño "no familiar ni patrimonial", el que alude a la pérdida de las relaciones de amistad que el inmigrante ha constituido en Chile. En esta materia, ha sido particularmente fecunda la labor efectuada por la CA de Iquique.

En definitiva, nos permitimos calificar como positiva la aludida y reciente interpretación, la que da muestra de una reacción por parte del Poder Judicial frente a uno de los desafíos planteados por los crecientes flujos migratorios que ha recibido Chile en las últimas décadas. De esta manera, se han reconocido derechos de gran relevancia de las personas, como lo es el derecho a fundar una familia y a recibir del Estado, con respecto a ésta, la correspondiente tutela jurídica. Especialmente lo anterior es relevante, dado que se ha otorgado protección a un colectivo que es víctima de continuas discriminaciones, como lo es la población inmigrante.

\section{BibliograFÍA CITADA}

Arnold, Rainer; MarTíneZ; José Ignacio, y ZúNiga, Francisco (2012): "El principio de proporcionalidad en la jurisprudencia del Tribunal Constitucionalidad", en Estudios Constitucionales (año 10, No 1), pp. 65-116. 
Audit, Bernard (2000): Droit international privè (3.a ed., Económica, París).

BARnÉS VÁSQueZ, Javier (1994): "Introducción al principio de proporcionalidad en el derecho comparado y comunitario", en Revista de Administración Pública (No 135), pp. 495-538.

Barrientos, Marcelo (2012): “¿El interés superior o inferior del niño? Aplicación jurisprudencial del artículo 42 de la Ley de Menores a la luz del Código Civil", en Elorriaga de Bonis, Fabián (coord.), Estudios de Derecho civil VII. Jornadas Nacionales de Derecho civil. Viña del Mar, 2011 (Thomson Reuters LegalPublishing, Santiago), pp. 117-126.

Bermúdez Soto, Jorge (1996): "El control de la discrecionalidad administrativa”, en Revista de Derecho de la Universidad Católica de Valparaiso (XVII), pp. 275-284.

Boettiger Philipps, Camila (2009): "El derecho administrativo sancionador en la jurisprudencia del Tribunal Constitucional", en Revista Actualidad Juridica (No 20, julio), pp. 577-596.

Mondaca Miranda, Alexis (2016): "La tutela de la familia versus la reincidencia del extranjero afectado por una resolución de expulsión. Corte de Apelaciones de Antofagasta, 5 de febrero de 2015", en Revista Chilena de Derecho Privado (No 27), pp. 293-301.

Mondaca Miranda, Alexis (2011): "Reflexiones sobre uno de los desafíos que la inmigración plantea al derecho de familia: los así denominados matrimonios de conveniencia", en Elorriaga de Bonis, Fabián (coord.), Estudios de Derecho civil IX. Jornadas Nacionales de Derecho civil, Viña del Mar, 2011 (Thomson Reuters - LegalPublishing, Santiago), pp. 41-54.

TAPIa Ladino, Marcela (2012): "Frontera y migración en el norte de Chile a partir del análisis de los censos de población. Siglos XIX-XXI”, en Revista de Geografia Norte Grande (No 53), pp. 177-198.

Tessada, José (2013): Inmigración en Chile. Diagnóstico y propuesta de politicas, (Pontificia Universidad Católica de Chile, Panel de Políticas Públicas CEP, Santiago).

\section{NORMAS JURÍDICAS CITADAS}

Decreto Ley No 1.094 de 1975, Ley de Extranjería. Diario Oficial de 19 de julio de 1975. 
Decreto Supremo No 597 de 1984, Reglamento de Extranjería. Diario Oficial de 24 de noviembre de 1984.

Ley No 19.947, Nueva Ley de Matrimonio Civil. Diario Oficial de 17 de mayo de 2004.

Ley No 28.830, Establece el Acuerdo de Unión Civil. Diario Oficial de 21 de abril de 2015 .

\section{JURISPRUDENCIA CITADA}

Contreras Mota con Intendencia de la Región de Arica y Parinacota (2017): Corte de Apelaciones de Arica 29 de marzo de 2017 (acción de amparo), rol No 73 2017, disponible en http:/www.pjuld.cl (visitado el 20.04.17).

Pérez Quevedo con Intendencia de la Región de Arica y Parinacota (2017): Corte de Apelaciones de Arica 29 de marzo de 2017 (acción de amparo), rol No 72 2017, disponible en http:/www.pjuld.cl (visitado el 20.04.17).

Aguilar Quispe con Ministerio del Interior y Seguridad Pública (2017): Corte de Apelaciones de Arica 17 de marzo de 2017 (acción de amparo), rol No 692017, disponible en http:/www.pjuld.cl (visitado el 20.04.17).

Huamán Almonacid con Intendencia de la Región de Arica y Parinacota (2017):

Corte de Apelaciones de Arica 10 de marzo de 2017 (acción de amparo), rol No 56-2017, disponible en http://www.pjuld.cl (visitado el 20.04.17).

Rodríguez de Corniel con Intendencia de la Región de Arica y Parinacota: Corte de Apelaciones de Arica 23 de diciembre de 2016 (acción de amparo), rol No 283-2016, disponible en http://www.pjuld.cl (visitado el 12.01.17).

Ramos Pérez con Intendencia de la Región de Arica y Parinacota: Corte de Apelaciones de Arica 23 de diciembre de 2016 (acción de amparo), rol No 282-2016, disponible en http://www.pjuld.cl (visitado el 23.02.17).

Jiménez Arnaud con Intendencia de la Región de Arica y Parinacota: Corte de Apelaciones de Arica 25 de noviembre de 2016 (acción de amparo), rol No 2242016, disponible en http://www.pjuld.cl (visitado el 9.02.17).

Mencia Beras con Intendencia de la Región de Arica y Parinacota: Corte de Apelaciones de Arica 2 de noviembre de 2016 (acción de amparo), rol No 158-2016, disponible en http://www.pjuld.cl (visitado el 9.02.17).

Baldera Tejada con Intendencia de la Región de Arica y Parinacota: Corte de Apelaciones de Arica 15 de julio (acción de amparo), rol No 86-2016, disponible en http://www.pjuld.cl (visitado el 9.02.17). 
Mejía Gross con Intendencia de la Región de Arica y Parinacota: Corte de Apelaciones de Arica 14 de julio (acción de amparo), rol No 84-2016, disponible en http://www.pjuld.cl (visitado el 9.02.17).

Bazalar Kori con Intendencia de la Región de Arica y Parinacota: Corte de Apelaciones de Arica 13 de junio (acción de amparo), rol No 77-2016, disponible en http://www.pjuld.cl (visitado el 9.02.17).

Gutiérrez Benzedu con Intendencia de la Región de Arica y Parinacota: Corte de Apelaciones de Arica 23 de diciembre (acción de amparo), rol No 151-2015, disponible en http://www.pjuld.cl (visitado el 8.02.17).

Huaman Almonacid con Intendencia de la Región de Arica y Parinacota: Corte de Apelaciones de Arica 3 de diciembre (acción de amparo), rol No 129-2015, disponible en http://www.pjuld.cl (visitado el 9.02.17).

Castro Eraso con Intendencia de la Región de Arica y Parinacota: Corte de Apelaciones de Arica 25 de octubre (acción de amparo), rol No 45-2013, disponible en http:/www.pjuld.cl (visitado el 9.02.17).

Ticona Choque con Intendencia Regional de Tarapacá (2017): Corte de Apelaciones de Iquique 11 de abril de 2017 (acción de amparo), rol No 36-2017, disponible en http://www.pjuld.cl (visitado el 2.05.17).

Payano con Intendencia Regional de Tarapacá (2017): Corte de Apelaciones de Iquique 29 de marzo de 2017 (acción de amparo), rol No 33-2017, disponible en http://www.pjuld.cl (visitado el 2.05.17).

Alburquerque con Intendencia Regional de Tarapacá (2017): Corte de Apelaciones de Iquique 17 de marzo de 2017 (acción de amparo), rol No 27-2017, disponible en http://www.pjuld.cl (visitado el 15.04.17).

Moreno Villa con Intendencia Regional de Tarapacá (2017): Corte de Apelaciones de Iquique 3 de marzo de 2017 (acción de amparo), rol № 21-2017, disponible en http://www.pjuld.cl (visitado el 15.04.17).

Mamani Limache y otro con Gobernación Provincial de Iquique (2017): Corte de Apelaciones de Iquique 3 de marzo de 2017 (acción de amparo), rol No 192017, disponible en http:/www.pjuld.cl (visitado el 15.04.17).

Suárez Riasco con Intendencia Regional de Tarapacá (2016): Corte de Apelaciones de Iquique 28 de noviembre de 2016 (acción de amparo), rol No 132-2016, disponible en http://www.pjuld.cl (visitado el 10.03.17).

Rodriguez Potter con Intendencia Regional de Tarapacá (2016): Corte de Apelaciones de Iquique 9 de noviembre de 2016 (acción de amparo), rol No 128-2016, disponible en http://www.pjuld.cl (visitado el 11.03.17). 
Solís Merino con Intendencia Regional de Tarapacá (2016): Corte de Apelaciones de Iquique, 7 de noviembre de 2016 (acción de amparo), rol No 123-2016, disponible en http://www.pjuld.cl (visitado el 11.04.17).

Manon Taveras con Intendencia Regional de Tarapacá (2016): Corte de Apelaciones de Iquique, 7 de noviembre de 2016 (acción de amparo), rol No 122-2016, disponible en http://www.pjuld.cl (visitado el 11.04.17).

Rúa Castillo con Intendencia Regional de Tarapacá (2016): Corte de Apelaciones de Iquique 12 de octubre de 2016 (acción de amparo), rol No 115-2016, disponible en http://www.pjuld.cl (visitado el 11.03.17).

Landázuri Castillo y otro con Gobernación Provincial de Iquique (2016): Corte de Apelaciones de Iquique 5 de septiembre de 2016 (acción de amparo), rol No 107-2016, disponible en http:/www.pjuld.cl (visitado el 15.04.17).

Gómez Gómez con Intendencia Regional de Iquique (2016): Corte de Apelaciones de Iquique 4 de agosto de 2016 (acción de amparo), rol No 94-2016, disponible en http://www.pjuld.cl (visitado el 15.04.17).

Baldera Almonte con Intendencia Regional de Tarapacá (2016): Corte de Apelaciones de Iquique 26 de julio de 2016 (acción de amparo), rol No 86-2016, disponible en http://www.pjuld.cl (visitado el 14.03.17).

Meléndez Pineda con Intendencia Regional de Tarapacá (2016): Corte de Apelaciones de Iquique 25 de julio de 2016 (acción de amparo), rol No 85-2016, disponible en http://www.pjuld.cl (visitado el 14.03.17).

León Núñez con Intendencia Regional de Tarapacá (2016): Corte de Apelaciones de Iquique 6 de julio de 2016 (acción de amparo), rol No 71-2016, disponible en http://www.pjuld.cl (visitado el 15.03.17).

Rodriguez Rodriguez con Intendencia Regional de Tarapacá (2016): Corte de Apelaciones de Iquique 30 de junio de 2016 (acción de amparo), rol No 66-2016, disponible en http://www.pjuld.cl (visitado el 15.03.17).

Ruiz Pérez con Intendencia Regional de Tarapacá (2016): Corte de Apelaciones de Iquique 22 de junio de 2016 (acción de amparo), rol No 63-2016, disponible en http://www.pjuld.cl (visitado el 15.02.17).

Muñoz con Intendencia Regional de Tarapacá (2016): Corte de Apelaciones de Iquique, 15 de junio de 2016 (acción de amparo), rol No 58-2016, disponible en http:/www.pjuld.cl (visitado el 28.04.17).

Vidal Banguera con Intendencia Regional de Tarapacá (2016): Corte de Apelaciones de Iquique 6 de junio de 2016 (acción de amparo), rol No 48-2016, disponible en http://www.pjuld.cl (visitado el 25.04.17). 
Cabrera Mesa con Intendencia Regional de Tarapacá (2016): Corte de Apelaciones de Iquique 3 de junio de 2016 (acción de amparo), rol No 47-2016, disponible en http://www.pjuld.cl (visitado el 13.02.17).

Guzmán con Intendencia Regional de Tarapacá (2016): Corte de Apelaciones de Iquique 30 de mayo de 2016 (acción de amparo), rol No 45-2016, disponible en http://www.pjuld.cl (visitado el 15.02.17).

Ramirez Flores con Policía de Investigaciones de Chile e Intendencia Regional de Tarapacá (2016): Corte de Apelaciones de Iquique 20 de mayo de 2016 (acción de amparo), rol No 42-2016, disponible en http://www.pjuld.cl (visitado el 15.02.17).

Zeballos Solano con Intendencia Regional de Tarapacá(2016): Corte de Apelaciones de Iquique 14 de abril de 2016 (acción de amparo), rol No 36-2016, disponible en http://www.pjuld.cl (visitado el 15.03.17).

Montoya Alavarez con Intendencia Regional de Tarapacá (2016): Corte de Apelaciones de Iquique 6 de abril de 2016 (acción de amparo), rol No 34-2016, disponible en http://www.pjuld.cl (visitado el 15.02.17).

Pérez Montero con Intendencia Regional de Tarapacá (2016): Corte de Apelaciones de Iquique 9 de marzo de 2016 (acción de amparo), rol No 31-2016, disponible en http://www.pjuld.cl (visitado el 15.02.17).

Muñoz Cifuentes con Intendencia Regional de Tarapacá y Policía de Investigaciones de Chile (2016): Corte de Apelaciones de Iquique 1 de febrero de 2016 (acción de amparo), rol No 9-2016, disponible en http:/www.pjuld.cl (visitado el 15.02.17).

Vásquez Carabali con Intendencia Regional de Tarapacá (2016): Corte de Apelaciones de Iquique 15 de enero de 2016 (acción de amparo), rol No 6-2016, disponible en http://www.pjuld.cl (visitado el 20.02.17).

Lozano Rivero con Intendencia Regional de Tarapacá (2016): Corte de Apelaciones de Iquique 15 de enero de 2016 (acción de amparo), rol No 7-2016, disponible en http://www.pjuld.cl (visitado el 20.02.17).

Castro Ramírez con Intendencia Regional de Tarapacá (2016): Corte de Apelaciones de Iquique 4 de enero de 2016 (acción de amparo), rol No 181-2015, disponible en http://www.pjuld.cl (visitado el 20.02.17).

Garcia Bacilio con Intendencia Regional de Tarapacá (2015): Corte de Apelaciones de Iquique 30 de diciembre de 2015 (acción de amparo), rol No 180-2015, disponible en http://www.pjuld.cl (visitado el 20.02.17). 
Martínez con Intendencia Regional de Tarapacá (2015): Corte de Apelaciones de Iquique, 30 de diciembre de 2015 (acción de amparo), rol No 179-2015, en http:/www.pjuld.cl (visitado el 20.04.17).

Mosquea García con Intendencia Regional de Tarapacá (2015): Corte de Apelaciones de Iquique, 31 de diciembre de 2015 (acción de amparo), rol No 178-2015, en http://www.pjuld.cl (visitado el 20.04.17).

De la Rosa Calcaño con Intendencia Regional de Tarapacá (2015): Corte de Apelaciones de Iquique 14 de diciembre de 2015 (acción de amparo), rol No 165-2015, disponible en http://www.pjuld.cl (visitado el 20.02.17).

Paniagua Acevedo con Intendencia Regional de Tarapacá (2015): Corte de Apelaciones de Iquique 11 de diciembre de 2015 (acción de amparo), rol No 164-2015, disponible en http://www.pjuld.cl (visitado el 20.02.17).

Sosa Reyes con Intendencia Regional de Tarapacá (2015): Corte de Apelaciones de Iquique 23 de noviembre de 2015 (acción de amparo), rol No 156-2015, disponible en http://www.pjuld.cl (visitado el 20.02.17).

Durán Reyes con Intendencia Regional de Tarapacá (2015): Corte de Apelaciones de Iquique 2 de noviembre de 2015 (acción de amparo), rol No 145-2015, disponible en http://www.pjuld.cl (visitado el 23.02.17).

Angulo Castillo con Intendencia Regional de Tarapacá (2015): Corte de Apelaciones de Iquique 22 de octubre de 2015 (acción de amparo), rol No 142-2015, disponible en http://www.pjuld.cl (visitado el 23.02.17).

Montoya con Policía de Investigaciones de Chile e Intendencia Regional de Tarapacá (2015): Corte de Apelaciones de Iquique 8 de octubre de 2015 (acción de amparo), rol No 141-2015, disponible en http://www.pjuld.cl (visitado el 23.02.17).

Constain Vallejos con Intendencia Regional de Tarapacá y Jefatura Nacional de Extranjería de la Policia de Investigaciones de Chile (2015): Corte de Apelaciones de Iquique 1 de octubre de 2015 (acción de amparo), rol No 131-2015, disponible en http://www.pjuld.cl (visitado el 23.02.17).

Garcés con Intendencia Regional de Tarapacá (2015): Corte de Apelaciones de Iquique 14 de septiembre de 2015 (acción de amparo), rol No 129-2015, disponible en http://www.pjuld.cl (visitado el 23.02.17).

Torres Santos con Intendencia Regional de Tarapacá (2015): Corte de Apelaciones de Iquique 17 de septiembre de 2015 (acción de amparo), rol No 128-2015, disponible en http://www.pjuld.cl (visitado el 23.02.17). 
De la Rosa Reyes con Intendencia Regional de Tarapacá (2015): Corte de Apelaciones de Iquique 23 de julio de 2015 (acción de amparo), rol No 101-2015, disponible en http://www.pjuld.cl (visitado el 23.02.17).

Muñoz Galvis con Intendencia Regional de Tarapacá (2015): Corte de Apelaciones de Iquique 20 de julio de 2015 (acción de amparo), rol No 100-2015, disponible en http:/www.pjuld.cl (visitado el 23.02.17).

Guerrero Mateo con Intendencia Regional de Tarapacá (2015): Corte de Apelaciones de Iquique 5 de junio de 2015 (acción de amparo), rol No 88-2015, disponible en http:/www.pjuld.cl (visitado el 23.02.17).

Cardona Ojeda con Intendencia Regional de Tarapacá (2015): Corte de Apelaciones de Iquique 21 de abril de 2015 (acción de amparo), rol No 58-2015, disponible en http://www.pjuld.cl (visitado el 15.02.17).

Hernández con Intendencia Regional de Tarapacá (2015): Corte de Apelaciones de Iquique 17 de marzo de 2015 (acción de amparo), rol No 49-2015, disponible en http:/www.pjuld.cl (visitado el 23.02.17).

Cortés Naraez con Intendencia Regional de Tarapacá (2015): Corte de Apelaciones de Iquique 13 de marzo de 2015 (acción de amparo), rol No 44-2015, disponible en http://www.pjuld.cl (visitado el 23.02.17).

Quintana Cozcon Intendencia Regional de Tarapacá (2015): Corte de Apelaciones de Iquique 25 de febrero de 2015 (acción de amparo), rol No 35-2015, disponible en http://www.pjuld.cl (visitado el 23.02.17).

Lozano Rivero con Intendencia Regional de Tarapacá (2015): Corte de Apelaciones de Iquique 11 de febrero de 2015 (acción de amparo), rol 24-2015, disponible en http://www.pjuld.cl (visitado el 23.02.17).

Palacios con Intendencia Regional de Tarapacá (2015): Corte de Apelaciones de Iquique 21 de enero de 2015 (acción de amparo), rol No 10-2015, disponible en http://www.pjuld.cl (visitado el 23.02.17).

Heredia con Intendencia Regional de Tarapacá (2015): Corte de Apelaciones de Iquique 16 de enero de 2015 (acción de amparo), rol No 7-2015, disponible en http://www.pjuld.cl (visitado el 23.02.17).

Lorenzo Pozo con Intendencia Regional de Tarapacá (2015): Corte de Apelaciones de Iquique 8 de enero de 2015 (acción de amparo), rol No 1-2015, disponible en http://www.pjuld.cl (visitado el 23.02.17).

Solís Recio y otro con Intendencia Regional de Tarapacá (2015): Corte de Apelaciones de Iquique 5 de diciembre de 2015 (acción de amparo), rol No 133-2014, disponible en http://www.pjuld.cl (visitado el 23.02.17). 
Bolivar Mota con Intendencia Regional de Tarapacá (2014): Corte de Apelaciones de Iquique 14 de octubre de 2014 (acción de amparo), rol No 102-2014, disponible en http://www.pjuld.cl (visitado el 23.02.17).

Wilson con Intendencia Regional de Tarapacá (2014): Corte de Apelaciones de Iquique 14 de octubre de 2014 (acción de amparo), rol No 98-2014, disponible en http://www.pjuld.cl (visitado el 23.02.17).

Martínez Angulo con Intendencia Regional de Tarapacá (2014): Corte de Apelaciones de Iquique 14 de octubre de 2014 (acción de amparo), rol No 97-2014, disponible en http://www.pjuld.cl (visitado el 26.02.17).

Ocoro Alomia con Intendencia Regional de Tarapacá (2014): Corte de Apelaciones de Iquique 3 de octubre de 2014 (acción de amparo), rol No 92-2014, disponible en http://www.pjuld.cl (visitado el 26.02.17).

Guzmán con Intendencia Regional de Tarapacá (2014): Corte de Apelaciones de Iquique 16 de septiembre de 2014 (acción de amparo), rol No 87-2014, disponible en http:/www.pjuld.cl (visitado el 26/02/17).

Ramirez Rengifo con Intendencia Regional de Tarapacá y Policia de Investigaciones de Chile (2014): Corte de Apelaciones de Iquique 11 de febrero de 2014 (acción de amparo), rol No 15-2014, disponible en http://www.pjuld.cl (visitado el 23.02.17).

Huanca Lovera con Intendencia Regional de Tarapacá (2014): Corte de Apelaciones de Iquique 29 de enero de 2014 (acción de amparo), rol No 9-2014, disponible en http://www.pjuld.cl (visitado el 23.02.17).

Ramos Portillo con Intendencia Regional de Tarapacá (2013): Corte de Apelaciones de Iquique 3 de julio de 2013 (acción de amparo), rol No 60-2013, disponible en http://www.pjuld.cl (visitado el 26.02.17).

Araníbar Viza y otro con Intendencia Regional de Tarapacá (2012): Corte de Apelaciones de Iquique 26 de octubre de 2012 (acción de amparo), rol No 98-2912, disponible en http://www.pjuld.cl (visitado el 26.02.17).

Huanca Ramos con Intendencia Regional de Antofagasta (2017): Corte de Apelaciones de Antofagasta 17 de marzo de 2017 (acción de amparo), rol No 67-2017, disponible en http://www.pjuld.cl (visitado el 10.04.17).

Anchico Torres con Intendencia Regional de Antofagasta (2017): Corte de Apelaciones de Antofagasta 25 de febrero de 2017 (acción de amparo), rol No 38-2017, disponible en http://www.pjuld.cl (visitado el 10.04.17). 
Rojas Pavón con Intendencia Regional de Antofagasta (2016): Corte de Apelaciones de Antofagasta 7 de diciembre de 2016 (acción de amparo), rol No 86-2016, disponible en http://www.pjuld.cl (visitado el 5.01.17).

Castro Villamán con Intendencia Regional de Tarapacá (2016): Corte de Apelaciones de Iquique, 23 de junio de 2016 (acción de amparo), rol No 62-2016, en http://www.pjuld.cl (visitado el 25.04.17).

Núnez Lopera con Departamento de Exranjería y Migración (2016): Corte de Apelaciones de Antofagasta 5 de octubre de 2016 (acción de amparo), rol No 60-2016, disponible en http://www.pjuld.cl (visitado el 12.01.17).

Montoya Reyes con Ministro del Interior (2016): Corte de Apelaciones de Antofagasta 2 de agosto de 2016 (acción de amparo), rol No 46-2016, disponible en http://www.pjuld.cl (visitado el 6.01.17).

Wagner Pizarro con Gobernación Provincial de Antofagasta (2016): Corte de Apelaciones de Antofagasta 29 de julio de 2016 (acción de amparo), rol No 452016, disponible en http://www.pjuld.cl (visitado el 5.01.17).

Cortés Blandón con Intendencia Regional de Antofagasta (2016): Corte de Apelaciones de Antofagasta 7 de abril de 2016 (acción de amparo), rol No 16-2016, disponible en http://www.pjuld.cl (visitado el 23.02.17).

Roque Roque con Departamento de Extranjería y Migración (2016): Corte de Apelaciones de Antofagasta 1 de abril de 2016 (acción de amparo), rol No 13-2016, disponible en http://www.pjuld.cl (visitado el 9.02.17).

Narváez Ortiz con Intendencia Regional de Antofagasta (2016): Corte de Apelaciones de Antofagasta 19 de febrero de 2016 (acción de amparo), rol No 8-2016, disponible en http://www.pjuld.cl (visitado el 7.03.17).

Parra Velásquez con Gobernación Provincial de Antofagasta y Departamento de Extranjería y Migración (2016): Corte de Apelaciones de Antofagasta 19 de enero de 2016 (acción de amparo), rol No 1-2016, disponible en http://www.pjuld. $\mathrm{cl}$ (visitado el 7.03.17).

Grillo Henao con Gobernación Provincial de Antofagasta (2015): Corte de Apelaciones de Antofagasta 9 de noviembre de 2015 (acción de amparo), rol No 67-2015, disponible en http://www.pjuld.cl (visitado el 5.01.17).

Osorio Minaya con Intendencia Regional de Antofagasta (2015): Corte de Apelaciones de Antofagasta 29 de octubre de 2015 (acción de amparo), rol No 65-2015, disponible en http://www.pjuld.cl (visitado el 20.02.17). 
Torres Klinger con Intendencia Regional de Antofagasta (2015): Corte de Apelaciones de Antofagasta 21 de agosto de 2015 (acción de amparo), rol No 51-2015, disponible en http://www.pjuld.cl (visitado el 20.02.17).

Omeregie con Intendencia Regional de Antofagasta (2015): Corte de Apelaciones de Antofagasta 5 de febrero de 2015 (acción de amparo), rol No 6-2015, disponible en http://www.pjuld.cl (visitado el 20.02.17).

González y otro con Departamento de Extranjería y Migración (2014): Corte de Apelaciones de Antofagasta 12 de agosto de 2015 (acción de amparo), rol No 45-2014, disponible en http://www.pjuld.cl (visitado el 5.01.17).

Romero Márquez con Gobernación Provincial de Antofagasta (2014): Corte de Apelaciones de Antofagasta 19 de junio de 2014 (acción de amparo), rol No 34-2014, disponible en http://www.pjuld.cl (visitado el 5.01.17).

Abella Llanten con Gobernación Provincial de Antofagasta (2014): Corte de Apelaciones de Antofagasta 13 de mayo de 2014 (acción de amparo), rol

No 26-2014, disponible en http:/www.pjuld.cl (visitado el 9.01.17).

Vélez Velásquez y otro con Intendencia Regional de Antofagasta (2014): Corte de Apelaciones de Antofagasta 22 de abril de 2014 (acción de amparo), rol No 22-2014, disponible en http://www.pjuld.cl (visitado el 22.01.17).

Ocampo Jiménez y otro con Gobernación Provincial de Antofagasta y Policia de Investigaciones de Chile (2014): Corte de Apelaciones de Antofagasta 19 de febrero de 2014 (acción de amparo), rol No 10-2014, disponible en http//www.pjul.cl (visitado el 23.01.17).

Caicedo Morales con Gobernación Provincial de Antofagasta e Intendencia Regional de Antofagasta (2014): Corte de Apelaciones de Antofagasta 24 de febrero de 2014 (acción de amparo), rol No 3-2014, disponible en http://www.pjuld. $\mathrm{cl}$ (visitado el 10.04.17).

Riascos Riascos Ramos con Intendencia Regional de Antofagasta (2014): Corte de Apelaciones de Antofagasta 8 de marzo de 2013 (acción de amparo), rol No 16-2013, disponible en http://www.pjuld.cl (visitado el 6.04.17).

Tapia Cueto con Intendencia Regional de Antofagasta (2012): Corte de Apelaciones de Antofagasta 1 de febrero de 2012, rol No 6-2012, disponible en $\mathrm{http//www.pjul.cl} \mathrm{(visitado} \mathrm{el} \mathrm{10.04.17).}$

Lina Grajales Vélez con Intendencia Regional de Atacama (2015): Corte de Apelaciones de Copiapó 1 de diciembre de 2016 (acción de amparo), rol No 3412015, disponible en http:/www.pjuld.cl (visitado el 17.03.17). 
Escobar Sandoval con Intendencia Regional de Atacama (2015): Corte de Apelaciones de Copiapó 16 de noviembre de 2016 (acción de amparo), rol No 328-2015, disponible en http://www.pjuld.cl (visitado el 17.03.17).

Aguasvivas con Intendencia Regional de Atacama (2013): Corte de Apelaciones de Copiapó 30 de octubre de 2013 (acción de amparo), rol No 355-2013, disponible en http://www.pjuld.cl (visitado el 10.03.17). 
